\title{
Facial Impaled Trauma Involving Anterior Cranial Fossa: Case Report
}

\section{Vingolo EM ${ }^{1}$, Arangio $\mathbf{P}^{2}$, Miscusi $\mathbf{M}^{3}$, Vellone $\mathbf{V}^{2}$ and Cascone $\mathbf{P}^{2}$}

${ }^{1}$ Department of Opthalmology, "Sapienza " University of Rome, Viale del Policlinico Rome, Italy

${ }^{2}$ Department of Maxillo-Facial Surgery, "Sapienza "University of Rome, Viale del Policlinico Rome, Italy

${ }^{3}$ Department of Neurosurgery, "Sapienza "University of Rome, Viale del Policlinico Rome, Italy

\begin{abstract}
An extraordinary case of trans-orbital penetrating injury is presented. A 42-year-old male was surprised while he was stealing into an apartment. While he was trying to escape through the window, he fell on a rod of the fence with not severe ocular and cerebral complications. We describe a unique presentation of a trans-orbital penetration injury that had a good outcome and not severe ocular and cerebral complications.
\end{abstract}

After being transported at the S.M. Goretti Hospital in Latina, the rod was removed outside the operating room and the CT scan was performed. Patient underwent urgent surgery after stabilization of vital parameters.

Keywords: Trans-orbital; Intracranial; Penetrating injury; Stab wounds; Craniofacial surgery; Impalement

\section{Introduction}

Trans-orbital intracranial injuries are relatively uncommon, representing about $0.4 \%$ of head injuries, as the adult skull usually provides an effective barrier to penetration while trans-orbital injuries represent up to $24 \%$ of penetrating head injuries in adults.

Impalement trauma often occurs accidentally and there are some cases reported in the literature, such as penetration of the skull by a steel bar but none with a good outcome and absence of ocular and cerebral complications.

For the treatment required a multidisciplinary team consisting of a neurosurgeon, ophthalmologist, maxillofacial surgeon, radiologists and anaesthesiologists. The orbit has a horizontal pyramid shape and any intra-orbital foreign body will either go through the weak frontal roof or will be directed to the apex of the orbit where there are two major openings, namely, the optic canal and the superior orbital fissure. Superior orbital fissure is larger than the optic canal. So it is more likely in this penetrating injury for the foreign body to pass through the first fissure than the second [1].

In this paper the authors present an interesting case of patient, victim of trans-orbital penetrating brain injury caused by a metal rod, with good recovery instead of the dramatically presentation documented by suggestive imaging.

\section{Case Report}

A 42-year-old male was surprised while he was stealing into an apartment. He tried to escape through the window, falling on a rod of the fence. The fire brigade intervention was necessary to cut the pole and transfer the impaled patient to the hospital (Figure 1). The patient arrived at the "S.M. Goretti Hospital" trauma Center in Latina, conscious and complete responsive with a 15 Points in Glasgow Coma Scale. External examination showed a right upper eyelid laceration greater than the diameter of the orbital rim, with a meter long metallic retained foreign body that hid the eyeball. Normal acuity and movements was observed in the left eye.

Neurosurgeon was consulted for the traumatic eyelid liquorrea. No other medical problems were found. The rod was incautiously removed in the Emergency Room, without any radiological control. Computed tomography showed a bone fracture of the right orbital roof, floor and zygoma, both frontal sinus and multi-density lesions in the bilateral frontal lobe, pneumocephalus and subarachnoid haemorrhage (Figure 2).

Surprisingly, the right ocular globe was intact because the "burst" fracture of the orbital compartment (a comminuted fracture of the floor, roof, lateral and medial orbital walls) allows the ocular globe to dodge and assume a downward displacement without being smashed against an osseous wall.

The planning of treatment required a multidisciplinary strategy. This particular demands the expertise of maxillo-facial surgeons, ophthalmologists and neurosurgeons cooperation. After surgery, the patient underwent post-operative CT showing a good fracture approximation (Figure 3 ). The patient was then moved to the intensive care unit and his neurological status remained constant; after three days, sedation was stopped and the patient was discharged from the intensive care unit. A large spectrum antimicrobial therapy (Gram+, Gram-, Anaerobics and Fungi) had been administering continuously during hospitalization because of the high risk of intracranial septic complications. The patient had no immediate significant complications except for a slight paresis of the right superior rectus; the ocular globe remained intact. Unfortunately the patient on the fourth day postoperative escaped from the hospital to avoid arrest by the police, not allowing us to make a long-term follow-up.

Regarding surgical approach, we performed a standard coronal incision with the bi-temporal flap elevation in a subgaleal plane up to the naso-frontal area. The pericranial flap was then outlined and pedicled anteriorly on the deep branches of the supraorbital and supratrochlear arteries. A subperiosteal dissection was then performed to elevate the pericranial flap from the skull to the level of the supraorbital rims. The fractured frontal sinus and anterior cranial fossa was exposed. A bifrontal craniotomy was performed and saved for replacement at the conclusion of surgery. Haemorrhagic and necrotic tissue was debrided

*Corresponding author: Valentino Vellone, Via Teano 35, Latina, Italy, Fax: +39 06 49979162; E-mail: valentino.vellone@gmail.com

Received October 23, 2014; Accepted March 23, 2015; Published March 26 , 2015

Citation: Vingolo EM, Arangio P, Miscusi M, Vellone V, Cascone P (2015) Facial Impaled Trauma Involving Anterior Cranial Fossa: Case Report. J Trauma Treat 4 238. doi:10.4172/2167-1222.1000238

Copyright: (c) 2015 Vingolo EM, et al. This is an open-access article distributed under the terms of the Creative Commons Attribution License, which permits unrestricted use, distribution, and reproduction in any medium, provided the original author and source are credited. 


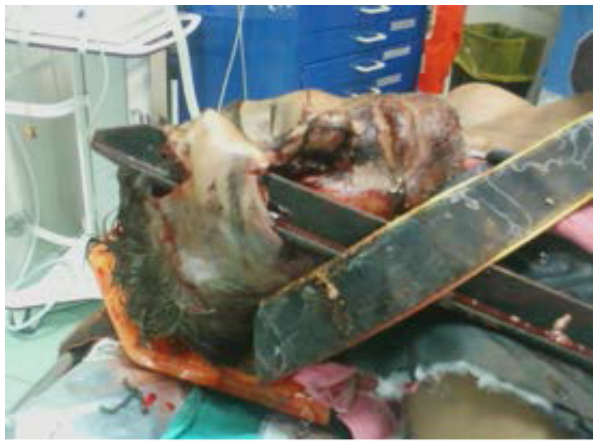

Figure 1: The Patient arrived in ER dept. with the rod passing through frontal area entering in the superior eyelid pushing the eye globe.

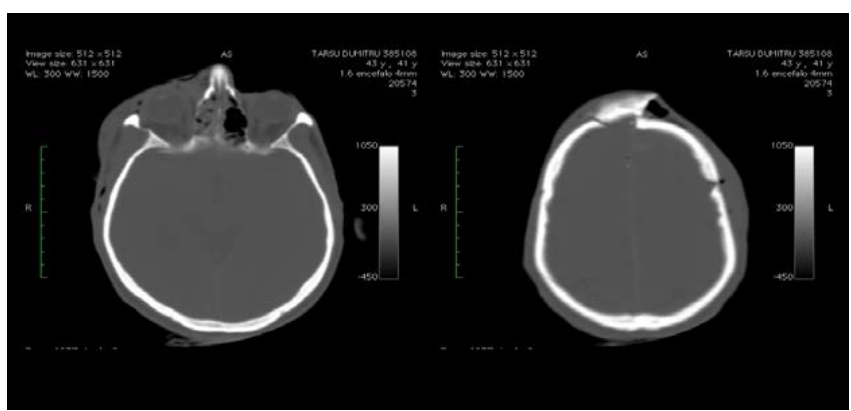

Figure 2: An assial CT scan showing fracture of the right zygoma without eye globe laceration.

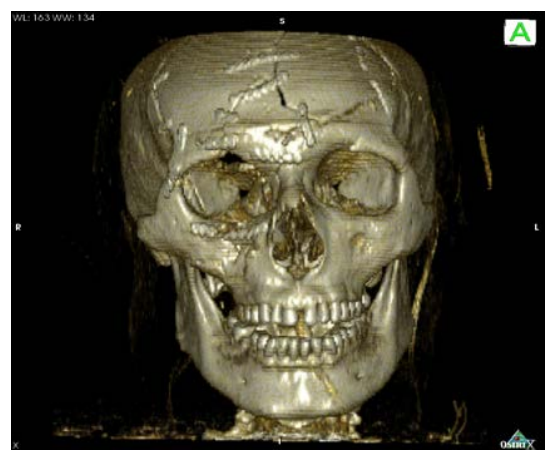

Figure 3: A 3D CT reconstruction in submental view showing the frontal fracture.

and the superior longitudinal sinus was clipped without difficulty. A large-scale duroplasty was performed with a bovine pericardial patch. Fibrin sealant was applied over the repair. The mucosa was removed from the frontal sinus walls as well as from the nasofrontal ducts. The pericranial flap is adapted in order to fit the anterior cranial fossa. The frontal volet was than replaced and secured with plates and screws. It's imperative to relieve any sharp bony edges off the anterior aspect of the bone flap to prevent injury to the vascular pedicle of the pericranial flap. After cranialization, the nasofrontal ducts was obliterated with a piece of temporalis fascia, fibrin glue is applied over the ducts, and the pericranial flap is designed appropriately and folded in order to obliterate the dead space of the sinus. The anterior wall was replaced and secured using plates and screws. All bony impingements on the vascular supply of the flap must be relieved. The bi-temporal flap was then closed in a layered fashion and a pressure dressing is applied and maintained for $48 \mathrm{~h}[2,3]$.
Right eyelid incision was performed to expose and reduce the margin fractured with titanium plates and screws. Collagen membrane was used for orbital floor reconstruction. In this clinical case, although trans-orbital cranio-cerebral injuries can present dramatic and especially dangerous, we have obtained a good functional recovery.

\section{Discussion}

Impalement injuries are perforating injuries caused by rod-like objects, producing a canal-shaped wound track corresponding to their length [1].

The literature provides a long list of objects known to have penetrated the brain that includes knives, pitchforks, crochet hooks, knitting needles, breech pins, umbrella bibs, crowbars and iron rods, car antennas and scissors [4-12].

Most of such injuries are caused by wooden branches, which carry a high risk of intracranial infection [13].

It has been shown that penetrating trauma can lead to intracerebral haematoma, cerebral contusion, intraventricular hemorrhage, brain stem injury and traumatic pseudoaneurysms as well as carotid cavernous fistulas [14].

Cranial and maxillofacial CT scan without contrast are the imaging studies of choice in these kind of trauma and can help to analyze the trajectory of the foreign body and to observe whether the object traverses any major vascular areas, including the ICA (especially within the cavernous sinus) and the anterior and middle cerebral arteries. In case of suspicion for vascular injury, angiography should also be performed to evaluate for traumatic aneurysm, which can develop soon after a penetrating injury [9-10].

Usually but not in reported case, the removal of the metal rod from the orbit and skull must be performed in the operating room, under radiological control, to avoid brain and vascular damage the early surgical treatment must be performed and is the best procedure to reduce infections occurrence rate. Penetrating objects, left in place until surgical removal, have a significantly lower mortality rate than removed before surgery (26\% vs. $11 \%$ respectively) [14]. Blind removal of the intracranial object is at risk of neurological and vascular damage if the trajectory is close to major vessels or important neural structures. Therefore an adequate surgical access allowing intracranial direct visualization of the object should be performed before its withdrawal [7]. Another possibility is to remove the foreign body under CT control with prompt detection and management of any complications; in this case, both operating room and angiographic team should be ready [9]. In patients with no CT evidence of intracranial haemorrhage or possible damage to vascular structures, the penetrating object, as in our subject, can be directly removed before surgical repair under general anaesthesia [10]. Even the trajectory of penetration excluded a major vascular injury; choice to withdraw the object blindly has been precipitous, because it could be fatal for the optic nerve and visual pathways, compromising the visual acuity.

According to literature, antibiotic therapy must be started on admission and although there are no data to support continuation after surgical removal, we strongly suggest in presence of cephalorachidian liquid leak continuing treatment three weeks, and in any case not less than one week $[9,10,15]$.

In our case right eyelid incision was performed to expose and reduce the margin fractured with titanium plates and screws. Collagen membrane was used for orbital floor reconstruction. 
Citation: Vingolo EM, Arangio P, Miscusi M, Vellone V, Cascone P (2015) Facial Impaled Trauma Involving Anterior Cranial Fossa: Case Report. J Trauma Treat 4: 238. doi:10.4172/2167-1222.1000238

Page 3 of 3

In most clinical case, although trans-orbital cranio-cerebral injuries can present dramatic and especially dangerous, it is possible to obtain a good functional recovery and marginal motory or sensorial damage.

\section{References}

1. Orszagh M, Zentner J, Pollak S (2009) Transorbital intracranial impalement injuries by wooden foreign bodies: clinical, radiological and forensic aspects. Forensic Sci Int 193: 47-55

2. Fattahi T, Dipasquale $\mathrm{J}(2009)$ Utility of the pericranial flap in frontal sinus and anterior cranial fossa trauma. Int J Oral Maxillofac Surg 38: 1263-1267.

3. Tedaldi M, Ramieri V, Foresta E, Cascone P, lannetti G (2010) Experience in the management of frontal sinus fractures. J Craniofac Surg 21: 208-210.

4. Pilcher C (1936) Penetrating wounds of the Brain: An experimental study. Ann Surg. 103: 173-198.

5. Markham JW, Mccleve DE, Lynge HN (1964) Penetrating Craniocerebral Injuries. Report of two unusual cases. J Neurosurg 21: 1095-1097.

6. Dooling JA, Bell WE, Whitehurst WR Jr (1967) Penetrating skull wound from a pair of scissors.Case report. J Neurosurg 26: 636-638.

7. Gulati A, Srinivasan B, Hunter R, Flood TR (2010) Penetrating knife injury to the frontal lobe-a case report. Ann R Coll Surg Engl 92: 41-42

8. Mitilian D, Charon B, Brunelle F, Di Rocco F (2009) Removal of a chopstick out of the cavernous sinus, pons, and cerebellar vermis through the superior orbital fissure. Acta Neurochir (Wien) 151: 1295-1297.

9. Schreckinger M, Orringer D, Thompson BG, La Marca F, Sagher O (2011) Transorbital penetrating injury: case series, review of the literature, and proposed management algorithm. J Neurosurg 114: 53-61.

10. Kim SW, Youn SK, Kim JT, Cho SH, Kim YH, et al. (2012) Management of an unusual craniofacial impalement injury by a metallic foreign body. J Craniofac Surg 23: 140-146.

11. Iwakura M, Kawaguchi T, Hosoda K, Shibata $Y$, Komatsu H, et al. (2005) Knife blade penetrating stab wound to the brain.Case report. Neurol Med Chir 45: 172-175.

12. Chibbaro S, Tacconi $L$ (2006) Orbito-cranial injuries caused by penetrating non-missile foreign bodies. Experience with eighteen patients. Acta Neurochir (Wien) 148: 937-941.

13. Haselsberger K, Oberbauer RW (1992) Extracranial-intracranial arterial bypass after cerebral foreign body embolization: effective treatment of transient ischemic attacks. Neurosurgery 31: 141-144.

14. De Villiers JC, Sevel D (1975) Intracranial complications of transorbital stab wounds. Br J Ophthalmol 59: 52-56.

15. Balasubramanian C, Kaliaperumal C, Jadun CK, Dias PS (2009) Transorbital intracranial penetrating injury-an anatomical classification. Surg Neurol 71 : 238-40. 